[0212-7199 (2005) 22: 4; pp 182-184] ALES DE MEDICINA INTERNA Copyright (C) 2005 ARAN EDICIONES, S.L.

AN. MED INTERNA (Madrid) Vol. 22, N. ${ }^{\circ} 4$, pp. 182-184, 2005

\title{
Síndrome antisintetasa sin afectación miosítica: a propósito de un caso
}

\author{
I. MARAÑÉS ANTOÑANZAS, Y. LÓPEZ GALLARDO, A. GARCÍA PARDO, \\ M. MIGUÉLEZ MORALES, M. L. ABELLA VÁZQUEZ, M. BETHENCOURT FERIA \\ Departamento de Medicina Interna. Complejo Hospitalario Universitario Nuestra Señora \\ Virgen de Candelaria. Santa Cruz de Tenerife
}

\begin{abstract}
ANTISYNTHETASE SYNDROME WITHOUT MYOSITIC DISEASE: A CASE REPORT
\end{abstract}

\section{RESUMEN}

El síndrome antisintetasa (SAS) es un trastorno infrecuente, incluido entre las miopatías inflamatorias idiopáticas, que se caracteriza por la presencia de anticuerpos antisintetasa (ACAS). Presentamos el caso de un paciente con cuadro clínico consistente en afectación intersticial pulmonar, alteraciones cutáneas y articulares, pero sin afectación muscular, junto con la presencia de anticuerpos anti-Jol.

PALABRAS CLAVE: Síndrome antisintetasa. Miopatía inflamatoria. Anti Jol. Enfermedad intersticial pulmonar.

\begin{abstract}
Antisynthetase syndrome is a rare disorder, included among the idiopathic inflammatory myopathies, characterized by the presence of antisynthetase antibodies. We present a case of a patient with a sugestive clinical stage of interstitial lung disease, skin and articular disease, but without muscle involvement, with the presence of anti Jol antibodies.
\end{abstract}

KEY WORDS: Antisynthetase síndrome. Inflammatory myopathy. Anti Jol. Interstitial lung disease.

Marañés Antoñanzas I, López Gallardo Y, García Pardo A, Miguélez Morales M, Abella Vázquez. ML, Bethencourt Feria M. Síndrome antisintetasa sin afectación miosítica: a propósito de un caso. An Med Interna (Madrid) 2005; 22: 182-184.

\section{INTRODUCCIÓN}

El síndrome antisintetasa (SAS) es un trastorno infrecuente, incluido entre las miopatías inflamatorias idiopáticas, que se caracteriza por la presencia de anticuerpos antisintetasa (ACAS). Estos anticuerpos son de tipo IgG dirigidos contra la enzima sintetasa, que media la unión del ARN con un determinado aminoácido, para formar el ARN de transferencia (ARNt) $(1,2)$. Siete autoanticuerpos han sido identificados hasta la fecha (anti-Jo1, anti-PL7, anti-PL12, anti-OJ, anti-EJ, anti-KS, anti-Wa), siendo el anti-Jo1 el mejor conocido (3). Anti-Jo1 fue identificado por primera vez en 1976, en el suero de un paciente con polimiositis y enfermedad intersticial pulmonar (4). En 1990 Marguerie y cols. (5), definieron el síndrome antisintetasa en función a un estudio retrospectivo de 29 pacientes con anti-Jo1 positivo. Anti-Jo1 se encuentra en $20-30 \%$ de los pacientes con miositis inflamatoria $(5,6)$, y se cree que sus títulos no se correlacionan con la severidad de los síntomas en esta entidad, pero sí con su curso, llegando a ser indetectables con tratamiento eficaz (7). Las manifestaciones clínicas principales del síndrome antisintetasa incluyen polimiositis o dermatomiositis, enfermedad intersticial difusa pulmonar, poliartritis, fenómeno de Raynaud y lesiones cutáneas eritemato-violáceas hiperqueratósicas sobre zonas de articulación metacarpofalángicas e interfalángicas (manos de mecánico) $(3,8)$. Entre estas manifestaciones la más frecuente es la enfermedad intersticial difusa pulmonar, que está presente en el $70 \%$ de los pacientes incluidos en los estudios principales. Es la enfermedad pulmonar intersticial la que domina el pronóstico del SAS, siendo la progresión a fibrosis difusa la norma en ausencia de tratamiento $(3,9)$.

\section{CASO APORTADO}

Se trata de un varón de 35 años de edad, sin hábitos tóxicos ni antecedentes clínicos de interés, que acude a urgencias por disnea. Dos meses antes del ingreso comienza con cuadro de disnea progresiva hasta hacerse de moderados y pequeños esfuerzos, acompañada de tos no productiva. Concomitantemente aparecieron lesiones cutáneas sobre las zonas metacarpofalángicas e interfalángicas proxima-

Trabajo aceptado: 3 de diciembre de 2004

Correspondencia: Ignacio Marañés Antoñanzas. C/ Fragua, 8B izq. (Urb. El Gramal) 38108 La Laguna. Santa Cruz de Tenerife. e-mail: nachomaranes@tiscali.es 
les que fueron diagnosticadas en un primer momento como eccema de contacto y posteriormente psoriasis, sin mejoría tras el tratamiento instaurado. Además refería dolor y tumefacción en las manos rodillas y codos.

En la exploración física destacaba una marcada desaturación con el esfuerzo, junto con crepitantes finos teleinspiratorios bibasales en la auscultación pulmonar. Presentaba lesiones difusas eritematodescamativas "psoriasis-like" en ambas manos y en codos (Fig. 1), así como dolor y tumefacción en la zona interfalángica proximal de varios dedos de las manos. En ambos párpados se objetivaba una zona de eritema violáceo muy llamativa (Fig. 2). Ausencia de mialgias a la exploración y anamnesis. No se encontraron otros datos de interés en la exploración

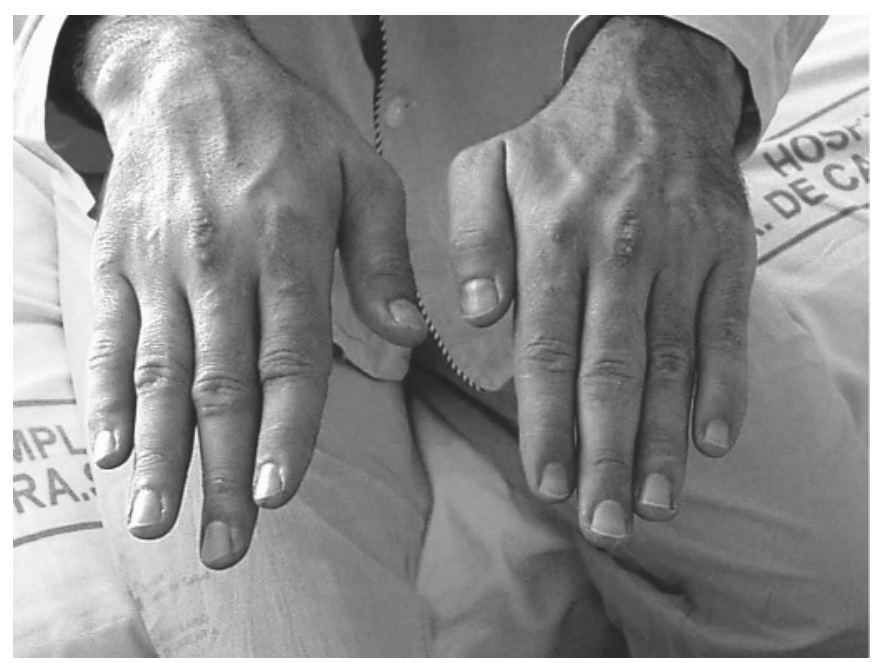

Fig. 1. Detalle de las lesiones eritematovioláceas y descamativas en manos "psoriasis-like" (manos de mecánico y signo de Gottron).

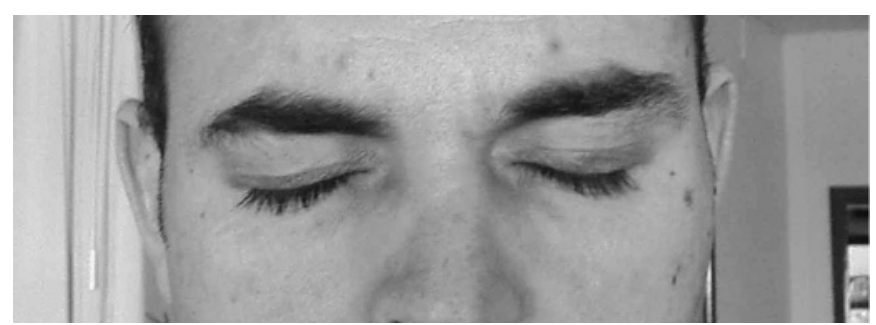

Fig. 2. Eritema violáceo en ambos párpados (eritema heliotropo).

Entre las pruebas complementarias destacaban una VSG de 49 $\mathrm{mm}$, con hemograma normal. Perfil hepático y renal, proteinograma, PCR y FR, CK y aldolasa en rango normal, ferritina $645 \mathrm{mg} / \mathrm{dl}$. ANAs, Acs. anti-Ro, ant-iRNP y anti-Scl negativos. Se detectaron anticuerpos anti-Jo1 positivos. Marcadores tumorales negativos. En la radiografía de tórax se podía apreciar un patrón fino intersticial bibasal, que se confirmaba en las imágenes tomográficas. En la espirometría se objetivó un patrón moderadamente restrictivo, junto con leve alteración de la difusión del monóxido de carbono. Se realizó un electromiograma que resultó normal.

Nuestro paciente presentaba estigmas cutáneos claros, como son las "manos de mecánico", "pápulas de Gottron" y eritema heliotropo, signos de artritis en las articulaciones de las manos y disnea progresiva con un patrón intersticial radiológico bilateral, y todo ello sin aparente afectación muscular, que se corroboró por medio de la clínica, determinaciones analíticas (CK y aldolasa) y un electromiograma.
Con estos datos realizamos un diagnóstico clínico dermatomiositis amiopática/síndrome antisintetasa.

Se inició tratamiento con corticoides (metilprednisolona) a dosis de $1 \mathrm{mg} / \mathrm{kg}$, con importante mejoría funcional de las articulaciones dañadas y con desaparición de las lesiones cutáneas. Semanas después del inicio del tratamiento hubo un rebrote de la enfermedad que coincidió con empeoramiento clínico-radiológico de la patología respiratoria, por lo que se planteó tratamiento con bolos de ciclofosfamida endovenosa y mantenimiento de corticoterapia. El paciente se sometió a 6 ciclos con importante mejoría clínica, que en el momento actual ha permitido el descenso de la corticoterapia, hallándose el paciente asintomático.

\section{DISCUSIÓN}

En los últimos años se han descrito casos de subgrupos de pacientes con enfermedad intersticial difusa pulmonar y anticuerpos antisintetasa en ausencia de miositis con un seguimiento de más de 10 años (10). Algunos estudios han demostrado que la aparición de neumonitis podía preceder en varios años a la miositis, en relación con anticuerpos Anti-PL12 (11).

Nuestro paciente presentaba patología pulmonar intersticial, junto con afectación artrósica y cutánea, en relación con anti-Jo1 positivos, todo ello sin datos clínicos ni analíticos de enfermedad muscular en los dos años posteriores al diagnóstico, ya que las enzimas musculares no se elevaron nunca y un nuevo electromiograma de control resultó negativo.

En cuanto a la enfermedad intersticial hay autores que han preconizado la detección de anticuerpos anti-Jo1 como despistaje de esta enfermedad, ya que el pronóstico es mejor frente a la fibrosis pulmonar idiopática, con respuestas positivas con tratamiento farmacológico. Respecto a dicho tratamiento se sabe poco ante la escasa experiencia con esta entidad, aparte de la corticoterapia estandarizada. Se han utilizado numerosos tratamientos inmunosupresores con desigual eficacia (azatioprina, metotrexato, ciclofosfamida y tacrolimus), e incluso se ha probado la inmunoglobulina endovenosa como tratamiento de $2^{\text {a }}$ línea (3). En el caso de la ciclofosfamida y tacrolimus se ha comprobado su eficacia en algunos estudios $(12,13)$. Nosotros elegimos la ciclofosfamida ante la mala evolución de la enfermedad pulmonar clínica y radiológicamente, descartando metotrexate ante una eventual toxicidad pulmonar. La respuesta tras los ciclos de terapia inmunosupresora fue claramente positiva, con rápida mejoría que ha permitido mantener dosis mínimas de corticoterapia en descenso.

En conclusión, podemos afirmar que se trata de un caso atípico de SAS con enfermedad intersticial pulmonar y sin afectación miosítica -durante un período de seguimiento de más de 2 años desde su diagnóstico-. Este ha sido el tiempo sugerido por algunos autores para establecer el diagnóstico firme de dermatomiositis amiopática $(14,15)$.

Es destacable asimismo la respuesta que presentó nuestro paciente tras el tratamiento con bolos de ciclofosfamida, tratándose de un fármaco inmunosupresor con escasa experiencia en esta entidad, y que hasta ahora había sido relacionado con una respuesta positiva en pacientes con afectación muscular extensa (16). 


\section{Bibliografía}

1. Maddison PJ. Aminoacyl-tRNA histidil (Jo-1) synthetase autoantibodies. Peter JB, Shoenfeld Y, editors. Autoantibodies. Elsevier Science, 1996. p. 31-5.

2. Targoff IN. Aminoacyl-tRNA (other than histidil) synthetase autoantibodies. Peter JB, Shoenfeld Y, eds. Autoantibodies. Elsevier Science, 1996. p. $36-46$

3. Imbert-Masseau A, Hamidou M, Agard C, Grolleau JY, Chérin P. Antisynthetase syndrome. Joint Bone Spine 2003; 70 (3): 161-8. Review.

4. Wasicek CA, Reichlin M, Montes M, Raghu G. Polymyiositis and interstitial lung disease in a patient with anti-Jo1 prototype.Am J Med 1984; 76: 538-44.

5. Marguerie C, Bunn CC, Beynon HL, Bernstein RM, Hughes JM, So AK. Polymyositis, pulmonary fibrosis and autoantibodies to aminoacyltRNA synthetase enzymes. Q J Med 1990; 77: 1019-38.

6. Kaminski H, Santillan C, Wolfe G. Autoantibody testing in neuromuscular disorders, part II: neuromuscular junction, hiperexcitability, and muscle disorders. J Clin Neuromusc Dis 2000; 2: 96-105.

7. Reichlin M, Arnett Jr FC, Multiplicity of antibodies in myositis sera. Arthritis Rheum 1984; 27: 1150-6.

8. Yazici Y, Kagen LJ. Clinical presentation of the idiopathic inflammatory myopathies. Rheum Dis Clin N Am 2002; 28: 823-32.
9. Villalobos RS, López-Campos Bodineau JL, Rodríguez Becerra. Síndrome antisintetasa y afección pulmonary intersticial. Descripción de 6 casos. Arch Bronconeumol 2002; 38 (10): 495-8.

10. Friedman AW, Targoff IN, Arnett FC. Interstitial lung disease with autoantibodies against aminoacyl-tRNA synthetases in the absence of clinically apparent myositis. Semin Arthritis Reum 1996; 26: 459-67.

11. Targoff IN, Arnett FC. Clinical manifestations in patients with antibody to PL-12 antigen (alanyl-tRNA synthetase). Am J Med 1990; 88: 24151 .

12. Al-Janadi M, Smith CD, Karsh J. Cyclophosphamide treatment of interstitial pulmonary fibrosis in polimyositis/dermatomyositis. J Rheumatol 1989; 16: 1592-6.

13. Oddis CV, Sciurba FC, Elmagd KA, Starzl TE. Tacrolimus in refractory polimyositis with interstitial lung disease. Lancet 1999; 353: 1762-3.

14. Climent-Albadalejo A, Saiz-Cuenca E, Rosique-Román J, CaballeroRodríguez J, Gálvez-Muñoz J. Dermatomyositis sine myositis and antisynthetase síndrome. Joint Bone Spine 2002; 69: 72-5.

15. Sontheimer RD. Cutaneus features of classic dermatomyositis and amyopathic dermatomyositis. Curr Opin Rheumatol 1999; 11: 475-82.

16. Bombardieri S, Hughes GR, Neri R. Cyclophosphamide in severe polymiositis. Lancet 1989; 1: 1138 . 